\title{
Médical interruption of pregnancy in the 2nd and 3rd trimester of pregnancy: about 42 cases collged at' the Tunis Maternity and Neonatology Center "Service A"
}

\section{Nebnomyidboumbou Norbert Wenceslas Djiguemde ${ }^{1 *}$, Timongo Francoise Danielle Millogo/Traore ${ }^{1}$, Jean Lankoande ${ }^{1}$, Dalenda Chanouffi/ Cheli ${ }^{2}$, Ezzidine Sfar ${ }^{2}$}

\author{
${ }^{1}$ Department of Obstetrics and Gynaecology, Yalgado Ouedraogo University Hospital Centre (CHU YO), Ouagadougou, \\ Burkina, Faso \\ ${ }^{2}$ Department of Obstetrics and Gynaecology, Maternity and Neonatal Centre of Tunis (CMNT), Service "A" Rabta
}

Received: 03 December 2021

Revised: 14 January 2022

Accepted: 15 January 2022

\section{*Correspondence: \\ Dr. Nebnomyidboumbou Norbert Wenceslas Djiguemde, \\ E-mail: norbertdijgo@gmail.com}

Copyright: (C) the author(s), publisher and licensee Medip Academy. This is an open-access article distributed under the terms of the Creative Commons Attribution Non-Commercial License, which permits unrestricted non-commercial use, distribution, and reproduction in any medium, provided the original work is properly cited.

\section{ABSTRACT}

Background: Study IMGs in the 2nd or 3rd trimester of pregnancy in department "A" of the CMNT.

Methods: Descriptive and analytical cross-sectional study in the "A" obstetrics gynecology department of the CMNT from January to June 2012. The variables studied related to sociodemographic characteristics, diagnosis, management and prognosis. Undiagnosed fetal abnormalities in the 1st trimester, serious maternal pathologies are the inclusion criteria. IMGs for embryofetopathies and MFIUs were not included in the study.

Results: The average age was 32 years with an average term of 27 weeks of amenorrhea and 01 day. The indication was $97.6 \%$ fetal. Fetal malformations were divided into $54.8 \%$ neurological abnormalities, $4.8 \%$ renal abnormalities, $4.8 \%$ digestive abnormalities, $4.8 \%$ bone abnormalities, $2.4 \%$ pulmonary abnormalities and $2.4 \%$ cardiac abnormalities. The foeto-pathological examination was carried out $64.3 \%$ confirming the antenatal diagnosis with an ultrasound sensitivity of $67.6 \%$ in the 2nd trimester and $83.3 \%$ in the 3rd trimester. The overall expulsion time was 30.6 hours $(<28$ SA) and 43.9 hours ( $>28$ SA), an overall success rate at 24 hours of $97.6 \%$ with one uterine rupture, 3 uterine retentions and hemorrhage. No cases of maternal death or infection were observed.

Conclusions: The delay in the diagnosis of fetal pathologies makes it difficult to decide on abortion for practitioners and parents. Antenatal ultrasound and fetal karyotype represented the means that made it possible to pose or suspect the diagnosis of fetal abnormality.

Keywords: Medical interruption 2nd and 3rd trimester, Fetal malformations, Dyschromosomia, Rubella, Fetopathology, Ultrasound sensitivity, CMNT

\section{INTRODUCTION}

Medical Interruption of Pregnancy in 2nd and 3rd Quarter: About 42 cases collected at the "A" service of the Tunis Maternity and Neonatology Center (CMNT) of the Rabta. Pregnancy medical interruptions (IMG) of the 2nd and 3rd quarter continue to worry about obstetricians as to the technique of their implementation. The sensitivity of ultrasound in the diagnosis of malformations is de rigueur. Misoprostol, an analog of prostaglandin E1, is used in obstetric gynecology, especially in the IMGs. IMG at 2nd and 3rd trimester of pregnancy should be rare. Screening for fetal malformations should be able to be done in the first quarter. If some detectable fetal annomials are curable, the most serious pathologies can lead to IMG. ${ }^{1,2}$ 


\section{METHODS}

\section{Study population and methods}

The "A" department of obstetrics gynecology of the "CMNT" of Rabta served as the Study Framework. Patients who consulted from January 2012 to June 2012 in whom the indication of IMG for fetal / maternal pathology constituted the study population.

\section{Study type}

The study is cross-sectional with a descriptive and analytical aim from January to June, 2012. Sources of data collection included maternal data, pregnancy follow-up, antenatal diagnosis results, ultrasound and MRI results, fetal sample results, protocol used and complications, fetal pathology results and neonatal characteristics.

\section{Inclusion criteria}

Undiagnosed fetal abnormalities in the 1st trimester, severe maternal pathology are the inclusion criteria.

\section{Non-inclusion criteria}

IMG for embryofoetopathies and MFIU Criteria for success and failure of the IMG method: success: pregnancy terminated completely without the need for suction or surgery, failure: use another method.

\section{Protocols used}

Between 14-28 SA

Mifégyne: $600 \mathrm{mg}$ orally once.

24 our intervals: Cytotec $400 \mu \mathrm{g}$ sublingually / 3 hours without exceeding five (5) doses.

\section{After 28 SA}

Cytotec $1 / 4$ tab intra vaginal, to be renewed every 8 hours. In case of hydrocephalus, puncture of the fetal head on expulsion. The study was submitted to the ethics committee for approval and the couple's consent was the basis before the start of the IMG procedure.

\section{RESULTS}

Epidemiology The total number of deliveries during the period was 2855. Cases of IMG in the 2 nd or 3 rd trimester 42 cases $(1.47 \%)$ including 41 cases of IMG for fetal indications $(97.6 \%)$ and one case for maternal indication (2.4\%). The average age was 32 with extremes of 19 and 42. Average gesture was 2 with extremes of 0 and 7 and the average parity of 1 with extremes of 0 s and 3 . Parental consanguinity was noted in $14.2 \%$ (6 cases). In the fetuses resulting from consanguineous unions, there were two cases of hydrocephalus, two cases of trisomy 21 , one case of bilateral hydrothorax and one case of large vessel transposition of the CAV type.

\section{Characteristics of IMGs for fetal indications}

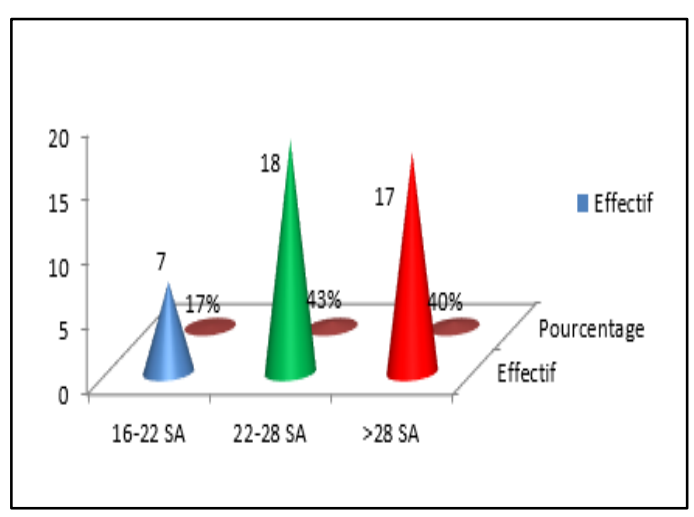

Figure 1: Distribution of IMGs according to gestational age.

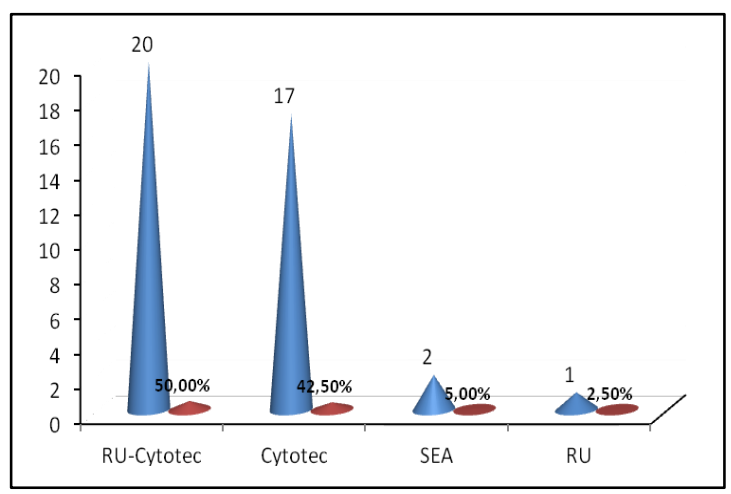

Figure 2: IMG protocols used.

The indications for IMG for fetal malformations were as follows.

$23(57.1 \%)$ cases of central nervous system (CNS) malformations, ie; 3 cases $(9.6 \%)$ of renal malformations; 3 cases $(9.6 \%)$ of digestive malformations; 1 case $(4.3 \%)$ of pulmonary malformations; 2 cases $(8.6 \%)$ of bone malformations; 1 case $(4.3 \%)$ of heart defects.

Table 1: Diagnostic sensitivity of the ultrasound in the 3rd trimester.

\begin{tabular}{|ll|}
\hline Ultrasound Sensitivity & Percent \\
\hline 2nd trimester & $67.6 \%$ \\
\hline 3rd trimester & $83.3 \%$ \\
\hline
\end{tabular}

\section{Indications for IMG for chromosomal aberration}

During the study, 4 cases of dyschromosomy (9.5\%), trisomy 21 were discovered. The mean age of ultrasound finding 21 weeks of amenorrhea (SA) and 6 days with extremes of $21 \mathrm{WA}$ and $22 \mathrm{WA}+6$ days. The diagnosis 
was confirmed by amniocentesis. The age of the parturients was 42 years ( 2 cases), 32 years ( 1 case) and 37 years (1 case).

\section{IMG indications for infectious pathology}

Rubella seroconversion was 3 cases $(7.1 \%)$. The average age of discovery is 22 weeks amenorrhea +5 days with extremes of 20 weeks and 25 weeks.

\section{Protocols used}

The effectiveness of IMG protocols

The overall efficiency was $97.6 \%$. The efficacy of mifepristone $200 \mathrm{mg}$ followed by misoprostol $200 \mu \mathrm{g}$ tablet was $100 \%$. The efficacy of misoprostol used alone was $92.30 \%$. The mean time to expulsion depending on the term: 30.6 hours $<28$ weeks of amenorrhea and 43.9 hours $\geq 28$ weeks of amenorrhea. The expulsion time according to the protocol was: For cytotec $₫$ alone 31.68 hours with extremes of 3 hours and 77.7 hours. For RU®-cytotec $₫$ : 48.55 hours [ 8 hours -154.5 hours].

\section{Complications}

Uterine rupture on a scarred uterus was confirmed on uterine revision on the old scar in $2.4 \%$ ( 1 case). Expulsion occurs after three doses of misoprostol. Placental retention $7.14 \%$ ( 3 cases) received additional management with 2 tablets of misoprostol and 2 others from a vacuum MVA. Bleeding from the medium abundance was noted in $2.4 \%$ (1 case) no maternal deaths were reported in our study.

\section{DISCUSSION}

\section{Epidemiology}

IMGs have globally increased in recent years. This was made possible by advances in fetal medicine and the development of antenatal diagnostic techniques. Previously, lethal fetal pathologies were only discovered at birth. The prevalence of medical terminations of pregnancy in the literature compared to our study is shown in Table 2.

Table 2: Prévalence comparée des IMG.

\begin{tabular}{|c|c|c|}
\hline Author & Study period & Frequency (\%) \\
\hline Marret $^{2}$ & 1992-1995 & 0.62 \\
\hline De Vigan ${ }^{3}$ & $1992-2000$ & 0.96 \\
\hline Aslan $^{4}$ & $2002-2006$ & 0.54 \\
\hline Our study & 2012 & 0.15 \\
\hline
\end{tabular}

\section{Characteristics of parturients}

The mean maternal age in our study was 32, with extremes of 19 and 42 . These results are comparable to those found in other recent series.

\section{Consanguinity}

It was observed in $85 \%$ of parturients. A study by Aslanet al4 noted consanguinity in situations of discovery of fetal malformations in $76.2 \%$.

Table 3: Comparison of maternal ages according to the authors.

\begin{tabular}{|llll|}
\hline Author & $\begin{array}{l}\text { Study } \\
\text { period }\end{array}$ & $\begin{array}{l}\text { Average } \\
\text { age } \\
\text { (years) }\end{array}$ & $\begin{array}{l}\text { Extreme } \\
\text { (years) }\end{array}$ \\
\hline Marret $^{2}$ & $1992-1995$ & 30 & $18-42$ \\
\hline Aslan $^{4}$ & $2002-2006$ & 27 & - \\
\hline $\begin{array}{l}\text { Our } \\
\text { study }\end{array}$ & 2012 & 32 & $19-42$ \\
\hline
\end{tabular}

Table 4: Distribution of indications for IMG according to the type of fetal anomaly.

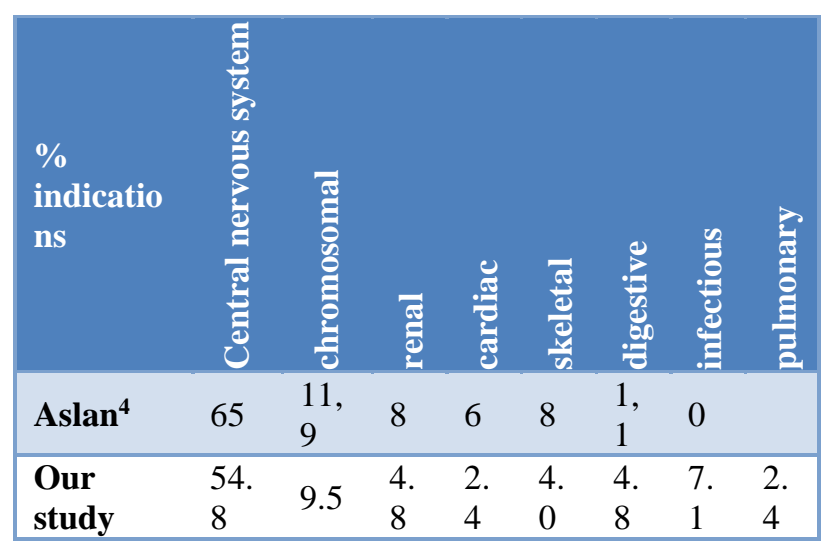

Table 5: Frequency of nervous system malformations.

\begin{tabular}{|c|c|c|c|c|c|c|c|}
\hline $\begin{array}{l}\% \text { of } \\
\text { neurological } \\
\text { malformatio } \\
\text { ns }\end{array}$ & 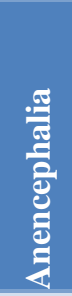 & 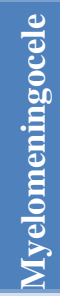 & 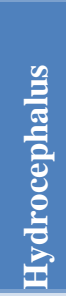 & $\begin{array}{l}\frac{\Delta}{8} \\
\frac{0}{0} \\
\frac{8}{0} \\
\frac{8}{0} \\
\frac{8}{0} \\
\frac{0}{0} \\
\frac{0}{0}\end{array}$ & $\frac{\frac{\partial}{E}}{\frac{\pi}{0}}$ & $\frac{2}{0}$ & 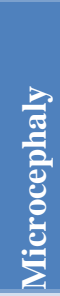 \\
\hline $\begin{array}{l}\text { Dommergue } \\
\mathrm{s}^{5}\end{array}$ & 7,1 & $\begin{array}{l}47 . \\
9\end{array}$ & $\begin{array}{l}35 . \\
2\end{array}$ & $\begin{array}{l}5 . \\
6\end{array}$ & $\begin{array}{l}4 . \\
2\end{array}$ & - & - \\
\hline Aslan 4 & $\begin{array}{l}34 . \\
9\end{array}$ & $\begin{array}{l}43 . \\
6\end{array}$ & 5.6 & $\begin{array}{l}5 . \\
6\end{array}$ & $\begin{array}{l}4 . \\
8\end{array}$ & $\begin{array}{l}5 . \\
5\end{array}$ & - \\
\hline Our study & $\begin{array}{l}17 . \\
4\end{array}$ & 8.7 & $\begin{array}{l}56 . \\
5\end{array}$ & $\begin{array}{l}4 . \\
3\end{array}$ & $\begin{array}{l}4 . \\
3\end{array}$ & - & $\begin{array}{l}8 . \\
7\end{array}$ \\
\hline
\end{tabular}

\section{Indication of IMG according to fetal abnormality}

\section{Fetal malformation}

Kidney malformations: represent between 6 and $8 \%$ of the causes of IMG. In our study, renal malformations accounted for $4.8 \%$ of indications for IMG and $7.1 \%$ of indications for IMG at a gestational age of 21 weeks and 2 days. This rate is comparable to that of Aslan (8\%). ${ }^{4}$ 
Bone malformations: They represent $2.4 \%$ of the causes of IMG. It was an osteochondrodysplasia and a case of IUGR abnormality associated with bilateral club feet and an omphalocele the causes of IMG for bone abnormalities constitute 3 to $13 \%$ according to Aslan and Pinto. ${ }^{4,6}$

Digestive malformations: These were 2 cases of omphalocele (4.8\%) of $27 \mathrm{~mm}$ containing stomach without associated abnormalities of ultrasound diagnosis at $17 \mathrm{WA}$ and 6 days and at 22 WA and 4 days. Survival in isolated omphalocele is $90 \%$ according to Creinin. ${ }^{7}$

Heart defects $2.4 \%$ cardiac abnormalities. This rate was lower than the results reported in the literature which vary between $4 \%$ and $9 \%$ Bonnefoy and Busken. ${ }^{8,9}$ Congenital heart disease diagnosed prenatally in France has increased over the past 25 years, from $23 \%$ in $1983-1988$ to $47.3 \%$ in 1995-2000 Busken. ${ }^{9}$

Chromosome aberration Chromosomal aberrations account for $9.5 \%$ of IMG. Trisomy 21, Down syndrome, 1 st place according to Khoshnood10. Trisomy's 13 and 18 represent one third of cases. Chromosomal abnormalities vary between $11.3 \%$ and $22.8 \%$ of the causes of IMG by Peterson and Sfar. ${ }^{11,12}$ Average age discovered 21 weeks and 6 days.

\section{Maternal indications}

Toxemia of pregnancy was the only case $(2.4 \%)$. It is rare because of the early detection and management of certain high-risk pregnancies.

\section{Ante natal exploration}

\section{Ultrasound Ultrasound}

Was the means that made it possible to make or suspect the diagnosis of fetal abnormalities in our study. Boog, the diagnostic performance of ultrasound varies depending on the fetal organ. ${ }^{13}$ The best detection rates are for CNS $(77.4 \%)$ and urinary tree $(66.1 \%)$ malformations. Ultrasound sensitivity is insufficient for skeletal abnormalities (34.4\%), trisomies (24.5\%) and heart defects $(18.7 \%)$. The average discovery term $21 \mathrm{SA}$ according to Amann and Baalbaky. ${ }^{14,15}$

\section{Amniocentesis}

The fetal karyotype was performed in $14.3 \%$ of cases. The fetal karyotype was performed in $9.5 \%$ of cases; this rate remained below the rates reported in the Western literature where ovular harvesting with genetic study was performed, on average, in $72 \%$ of IMG cases. ${ }^{6}$ No karyotype was indicated from the outset in front of an advanced maternal age, over 35 years, but also in front of ultrasound abnormalities. The indications of fetal karyotype for abnormally thick nuchal translucency represent $13 \%$ of the indications according to a study by Chaabouni. ${ }^{16}$
Table 6: Comparative study of the diagnostic sensitivity of ultrasound in the 2nd trimester.

\begin{tabular}{|lllll|}
\hline & $\begin{array}{l}\text { Our } \\
\text { study }\end{array}$ & $\begin{array}{l}\text { Hélène } \\
\text { Grandjean }\end{array}$ & Stefos & $\begin{array}{l}\text { Other } \\
\text { authors }\end{array}$ \\
\hline $\begin{array}{l}\text { Global } \\
\text { sensitivity }\end{array}$ & $\begin{array}{l}67.6 \\
4 \%\end{array}$ & $61.4 \%$ & $80 \%$ & \\
\hline $\begin{array}{l}\text { Neurological } \\
\text { abnormalities }\end{array}$ & $\begin{array}{l}68.2 \\
\%\end{array}$ & $88.3 \%$ & $93 \%$ & $\begin{array}{l}71 \% \\
\mathrm{Vos}^{24}\end{array}$ \\
\hline $\begin{array}{l}\text { Heart and } \\
\text { great vessel } \\
\text { abnormalities }\end{array}$ & $0 \%$ & $38.8 \%$ & $45 \%$ & $\begin{array}{l}\text { Rustico } \\
25\end{array}$ \\
\hline $\begin{array}{l}\text { Limb } \\
\text { abnormalities }\end{array}$ & $\begin{array}{l}16.2 \\
\%\end{array}$ & $37 \%$ & & $\begin{array}{l}36 \% \\
\text { Stoll }\end{array}$ \\
\hline
\end{tabular}

Table 7: Comparative study of ultrasound sensitivity in the 3rd trimester.

\begin{tabular}{|llll|}
\hline & $\begin{array}{l}\text { Our } \\
\text { study }\end{array}$ & $\begin{array}{l}\text { Hélène } \\
\text { Grandjean }\end{array}$ & Stefos $^{23}$ \\
\hline $\begin{array}{l}\text { Global } \\
\text { sensitivity }\end{array}$ & $83.3 \%$ & $88 \%$ & $91 \%$ \\
\hline $\begin{array}{l}\text { Neurological } \\
\text { abnormality }\end{array}$ & $100 \%$ & $\begin{array}{l}71 \% \text { (spina- } \\
\text { bifida) }\end{array}$ & \\
\hline $\begin{array}{l}\text { Heart and } \\
\text { great vessel } \\
\text { abnormalities }\end{array}$ & $100 \%$ & & \\
\hline $\begin{array}{l}\text { Urogenital } \\
\text { abnormalities }\end{array}$ & $0 \%$ & $89 \%$ & $84.8 \%$ \\
\hline $\begin{array}{l}\text { Lung and } \\
\text { thorax } \\
\text { abnormalities }\end{array}$ & $0 \%$ & $70 \%$ & - \\
\hline
\end{tabular}

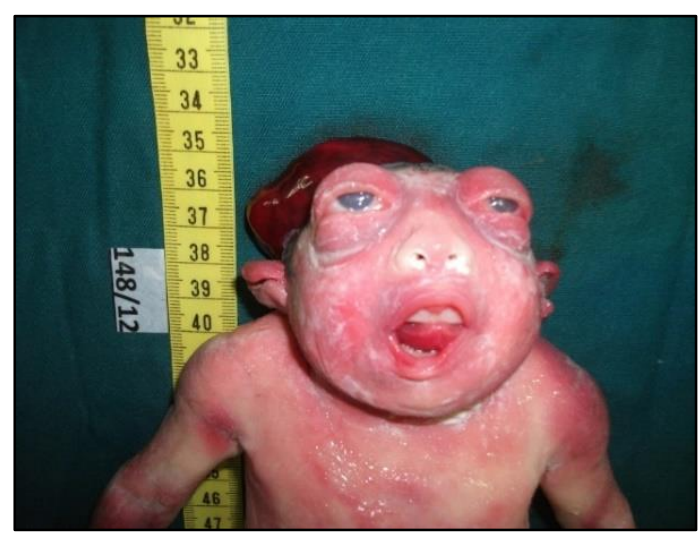

Figure 3: Anencephaly.

\section{IMG protocols}

\section{Effectiveness of protocols}

The overall efficiency rate $97.6 \%$. The efficacy of mifepristone in combination with misoprostol was $100 \%$ versus $92.30 \%$ with misoprostol alone. Our rate is comparable to that of Mazouni et al With a success rate of $99.2 \%$ for a term of pregnancy of more than 15 weeks. ${ }^{18}$ 
Chawdhary et al. The success rate $94 \%$ misoprostol and mifepristone and $86 \%$ misoprostol alone. ${ }^{17}$

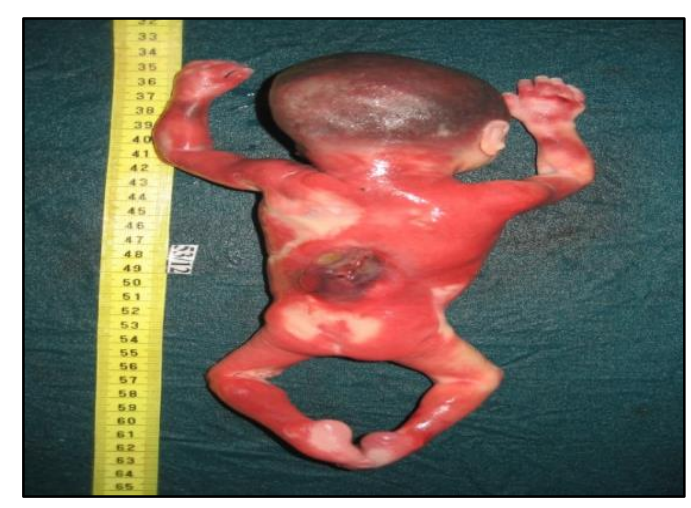

Figure 4: Myelomeningocele.

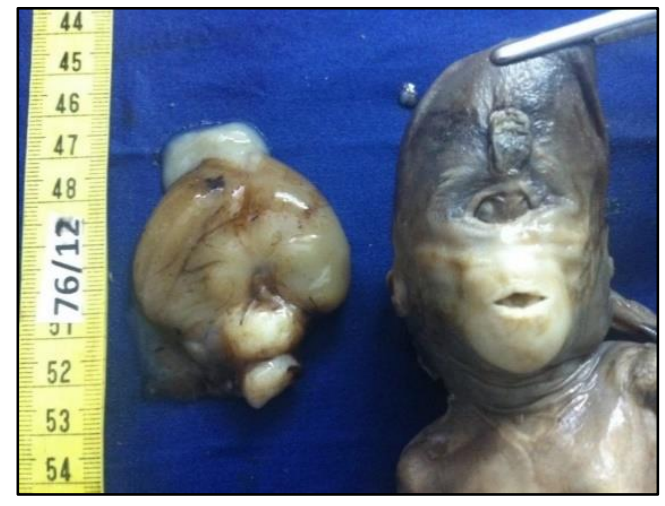

Figure 5: Alobar Holoproencephaly.

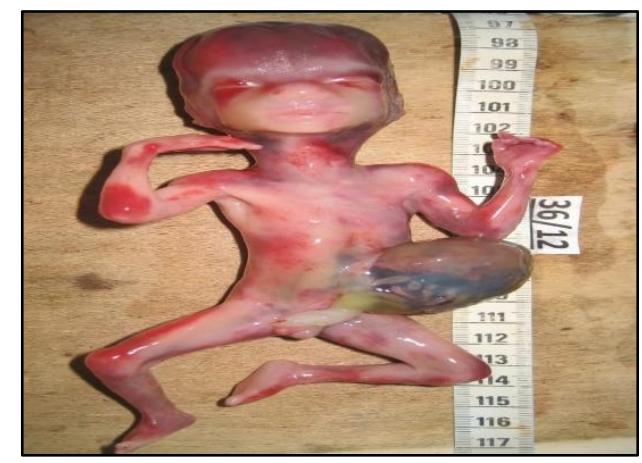

Figure 6: 35mm Omphalocele (liver, intestine, spleen).

\section{Expulsion period}

The average time to expulsion of 40.1 hours with extremes of 3 hours 25 minutes to 154 hours 30 minutes. The average time to expulsion according to the term of pregnancy was 30.6 hours for pregnancies less than 28 weeks and 43.9 hours for pregnancies greater than or equal to 28 weeks. Complications No case of maternal death reported in the study. It is comparable to that of Ellertson, who notes a risk of partial or complete retention between $2.5 \%$ and $6 \% .{ }^{19}$ we recorded a uterine rupture $(2.4 \%)$. It is around $1.5 \%$ in the literature. Letourneur in his study noted
$0.1 \%$ and $1 \%$ of cases of rupture of a scarred uterus after the administration of $1400 \mathrm{~g}$ orally of misoprostol, from $0.3 \%$ to $4 \%$ in women in labor. ${ }^{20}$ According to Dodd, the use of misoprostol causes uterine-type complications in the 2 nd and 3rd trimesters. ${ }^{21}$

\section{Ultrasound sensitivity}

\section{Patient follow-up}

It is provided by support from the team in the labor and delivery room, monitoring of constants. Systematic injection of anti-D gamma globulins in negative rh patients or after checking for irregular agglutinins and informing of the possibility of bleeding onset within 48 hours after taking the drugs.

\section{Limitations of the study}

Due to the size of our study population, the statistical tests we apply are lacking power to affirm the certainty of certain links between factors.

\section{CONCLUSION}

The antenatal diagnosis of fetal anomalies has made progress for antenatal and post-natal adapted support. The discovery of certain lethal abnormalities or engaging the neonatal prognosis can lead to the practice of an IMG. The delay in the diagnosis of a malformation, chromosomal abnormality or infection with fetal repercussions makes it difficult to make the decision to interruption of pregnancy for practitioners and parents. The purpose of our study was to make the inventory of IMG for fetal and kindergarten indications. Antenatal ultrasound and fetal caryotype have shown the means having made or suspect the diagnosis of fetal anomaly. The current practice of the IMG puts practitioners, both obstetrian and neonatalogist, in front of difficult ethical dilemmas. Thus late IMG can lead, depending on the indication and the absence of feticidal act, viable births. The appropriate method for achieving an IMG decision is the consultation between obstetricians, neonatalogists, geneticists, radiologists, psychologists and lawyers. Throughout this approach, parents must be informed and informed of possible outcomes.

Funding: No funding sources Conflict of interest: None declared

Ethical approval: The study was approved by the Institutional Ethics Committee

\section{REFERENCES}

1. Marret H, Perrotin F, Descamps A, Lansac J, de Magalhaes A, Body G. Interruption médicale de grossesse aux 2èmes et 3èmes trimestres. A propos de 125 indications de 1992 à 1995 . J Gynecol Obstet Biol Reprod. 1999; 28:245-52.

2. De Vigan C, Khoshnood B, Lhomme A. Prévalence et diagnostic prénatal des malformations en population 
parisienne. J Gynecol Obstet Biol Reprod. 2005; 34:816.

3. Aslan H, Yildirim G, Ongutb C, Ceylan Y. Termination of pregnancy for fetal anomaly. International Journal of Gynecology and Obstetrics. 2007;99:221-4.

4. Dommergues M, Benachi A, Benifla JL, des Noettes $\mathrm{R}$, Dumez $\mathrm{Y}$. The reasons for termination of pregnancy in the third trimester. Br J Obstet Gynecol. 1999;106(4):297-303.

5. Escalante PD, Zapata CI, Allec RD. Spectrum of congenital malformations observed in neonates of consanguineous parents. An Pediatr (Barc). 2006;64:5-10.

6. Creinin MD, Schwartz JL, Guido RS, Pymay HC. Early Pregnancy Failure-Current Management Concepts. Obstetrical and Gyncological Survey. 2001;56(2):105-13.

7. Bonnefoy R, Poinsot J, Vaillant MC, Chantepie A. Evolution du diagnostic anténatal des cardiopathies congénitales entre 1991 et 2005 dans une population limitée au département d'Indre-et-Loire. Arch Pediatr. 2011;18:512-7.

8. Buskens E, Grobbee DE, Frohn-Mulder IME. Efficacy of Routine Fetal Ultrasound Screening for Congenital Heart Disease in Normal Pregnancy. Circulation. 1996;94:67-72.

9. Khoshnood B, de Vigan C, Vodovar V, Goujard J, Goffinet F. A population-based evaluation of the impact of antenatal screening for Down's syndrome in France, 1981-2000. BJOG. 2004;111:485-90.

10. Peterson CC. A review of biochemical and ultrasound markers in the detection of Down's syndrome. Journal of Perinatal Education. 2006;15:19-25.

11. Sfar E, Hendaoui Med S, Bitri M, Siala, Chelli H. Indications de l'interruption médicale de la grossesse (IMG) au cours des anomalies fœtales diagnostiquées in utero. Tunisie médicale. 1997;75(nº 10$): 750-3$.

12. Georges Boog. Performances et limites de l'échographie obstétricale. EMC Obstétrique [5-003A-10] Amann J-P. Diagnostic prénatal et interruption médicale de grossesse : aspects éthiques. J Pédiatr Puériculture. 2003;16:147-55.

13. Baalbaky I, Manouvrier S, Dufour P. Le diagnostic anténatal de l'ostéogenèse imparfaite : à propos de deux observations. J Gynecol Obstet Biol Reprod. 1998;27:44-51.

14. Chaabouni H, Chaabouni M, Maazoul F, M'Rad R, Jemaa L, Zouari F. Prenatal diagnosis of chromosome disorders in Tunisian population. Annales de génétique. 2001;44:99-104.
15. Chawdhary R, Rana A, Pradhan N. Mifepristone plus misoprostol par voie vaginale vs misoprostol par voie vaginale seule pour l'avortement médicamenteux en gestation de 63 jours ou moins dans les femmes népalaises: un quasi-randomisée et contrôlée trial. J Obstet Gynaecol Res. 2009;35(1):78-85.

16. Mazouni C, Provensal M, Porcu G, B Guidicelli, Heckenroth H. Misoprostol-induced termination of second trimester pregnancy in women with a history of cesarean section: A retrospective analysis of 56 cases. Ginekol Pol. 2013 ;84 :277-80.

17. Contraception césarienne précédente. 2006;73(3):244-8.

18. Ellertson C, Waldman S. The MifepristoneMisoprostol Regimen for Early Medical Abortion. Current Women's Health Reports. 2001;1:184-90.

19. Letourneur B, Parant O, Tofani V, Berrebi A. Fédération de Gynécologie-Obstétrique, CHU Toulouse-La Grave, place Lange, 31052 Toulouse. Uterine rupture on unscared uterus following labor induction for 2 nd trimester termination of pregnancy with oral misoprostol: conservative management. Journal de Gynécologie Obstétrique et Biologie de la Reproduction. $2002 ; 31\left(n^{\circ} 4\right): 371-3$.

20. Dodd JM, Crowther CA. Misoprostol contre cervagem pour l'induction du travail de mettre fin à la grossesse dans le deuxième et le troisième trimestre: une approche systématique. J Obstet Gynecol Reprod Biol. 2006;125(1):3-8.

21. Grandjean H, Larroque D, Levi S, and the Eurofetus team. The performance of routine ultrasonographic screening of pregnancies in the Eurofetus study. Am J Obstet Gynecol. 1999;181:446-54.

22. Stefos T. Routine obstetrical ultrasound at 18-22 weeks: our experience on 7236 fetuses. J Matern Fetal Med. 1999;8:64-9.

23. Vos JM. Sensitive and specific screening for detection of spina bifida by echography in the second trimester; systematic review and meta-analysis Ned Tijdschr Geneeskd. 2000;144:1736-41.

24. Rustico MA, Benettoni A, D'Ottavio G, FischerTamaro L, Conoscenti GC, Meir Y et al. Early screening for fetal cardiac anomalies by transvaginal echocardiography in an unselected population: the role of operator experience. Ultrasound ObstetGynecol. 2000;16:614-9.

25. Stoll C. Evaluation of the prenatal diagnosis of limb reduction deficiencies. Prenat Diagn. 2000;20:812-8.

Cite this article as: Djiguemde NNW, Traore TFDM, Lankoande J, Cheli DC, Sfar E. Médical interruption of pregnancy in the 2nd and 3rd trimester of pregnancy: about 42 cases collged at the Tunis Maternity and Neonatology Center "Service A". Int J Reprod Contracept Obstet Gynecol 2022;11:332-7. 